\title{
Pola Penyebaran Pesan Melalui Akun Facebook pada Karyawan Generasi Milenial di PT. XXX Indonesia
}

\author{
Ulani Yunus ${ }^{1}$, Gustina ${ }^{2}$ \\ ${ }^{1,2}$ Research Interest Group Cross-Culture Communication, \\ Universitas Bina Nusantara \\ Jl.KH Syahdan No. 9 Jakarta Barat 11480 - Indonesia \\ Corresponding author: uyunus@ binus.edu
}

\begin{abstract}
This study aims to provide an overview of the pattern of the distribution of messages by Millennial Generation as employees through Facebook. This research was conducted because the Millennial Generation is the majority in Indonesia, which is 1 in 3 of Indonesia's population, as well as the number of companies; Facebook $(F B)$ is a social media that ranks first in the world as the most widely used social media. This study uses a descriptive qualitative approach. The research method used is a case study with data collection techniques in the form of open interviews and observations. The results obtained from this study are there are patterns of distribution of messages through FB by millennial generation through good news in the form of photos or writing between their working hours. FB is also a medium that is a source of news that is distributed by personal accounts. The company's FB account does not get the attention of employees so it is not suitable to disseminate information for internal purposes.
\end{abstract}

Keywords: Facebook, Millennial Generation, Pattern of spreading message.

\begin{abstract}
Abstrak
Penelitian ini bertujuan untuk memberikan gambaran mengenai pola penyebaran pesan yang oleh Generasi Milineal sebagai karyawan melalui Facebook. Penelitian ini dilakukan karena Generasi Milenial menjadi mayoritas di Indonesia, yaitu 1 dari 3 jumlah penduduk Indonesia, demikian juga jumlah yang ada pada perusahaan; Facebook (FB) adalah media sosial yang menempati posisi pertama di dunia sebagai media sosial yang paling banyak digunakan. Penelitian ini menggunakan pendekatan kualitatif dengan jenis deskriptif. Metode penelitian yang digunakan adalah studi kasus dengan teknik pengumpulan data berupa wawancara terbuka dan observasi. Hasil yang diperoleh dari penelitian ini adalah terdapat pola penyebaran pesan melalui FB oleh generasi milenial melalui berita baik dalam bentuk foto atau tulisan sela-sela jam kerja mereka. FB juga merupakan media yang menjadi sumber berita bohong yang disebarkan oleh akun pribadi. Akun FB perusahaan tidak mendapat perhatian karyawan sehingga tidak cocok untuk menyebarkan informasi untuk kepentingan internal
\end{abstract}

Kata Kunci: Facebook, Milenial, Karyawan, Pola Penyebaran Pesan

Copyright @ 2018 Ikatan Sarjana Komunikasi Indonesia. All rights reserved

\section{PENDAHULUAN}

Pada abad ke-21 saat ini, banyak generasi $Y$ yang telah menggantikan generasi sebelumnya dalam memegang peran penting di berbagai hal seperti di perusahaan ataupun industri. Generasi $\mathrm{Y}$ atau lebih dikenal dengan sebutan generasi millenial atau millennium adalah generasi yang tumbuh pada era internet booming (Lyons, 2004). Menurut Markert, generasi milenial adalah generasi milenial yang lahir di antara tahun 1986 sampai tahun 2005 (Markert, 2004). Generasi milenial hidup dalam era digital di mana generasi ini tumbuh bersamaan dengan kemajuan digital dan komputerisasi seperti telepon, handphone, smartphone dan internet. 
Salah satu teknologi yang berkembang pesat sebagai media yang paling banyak dikonsumsi oleh generasi milenial adalah media sosial. Kaplan dan Haenlein mendefinisikan media sosial sebagai "sebuah kelompok aplikasi berbasis internet yang dibangun di atas dasar ideologi dan teknologi Web 2.0. dan memungkinkan penciptaan dan pertukaran user-generated content" (Kaplan \& Haenlein, 2010). Nama media sosial adalah Line, Twitter, Instagram dan yang paling sering digunakan oleh generasi Y saat ini adalah Facebook. Data ini di peroleh dari Hootsuite dan We are Social pada April 2017, dimana Facebook menempati posisi pertama di dunia dari 21 media sosial dengan 1,9 juta pengguna (Ismarani, 2017).

Facebook adalah salah satu media sosial yang terkenal dalam kategori situs jejaring sosial karena menghubungkan orang-orang di seluruh dunia. Melalui Facebook, pengguna dapat menampilkan profil diri lengkap dengan foto-foto, bersosialisasi dengan orang-orang yang punya hobi sama, menjadi fans artis, berbagi cerita dan kegiatan, atau chatting online dengan pengguna lain (Ikom, 2014). Kemunculan media sosial Facebook mempengaruhi perilaku dan kebiasaan para generasi milenial karena ada kecenderungan untuk selalu memeriksa, melakukan update dan mengunggah foto, kegiatan, pendapat ke akun facebook pribadi mereka. Hal ini dilansir dari CNN mengenai sebuah penelitian yang dilakukan oleh International Data Corporation (IDC) untuk menghitung seberapa sering pengguna Facebook memeriksa akun mereka dalam satu hari.

Dari hasil penelitian tersebut, ditemukan fakta bahwa rata-rata para pengguna smartphone tersebut memeriksa akun Facebook mereka sebanyak 14 kali setiap harinya. Setiap kali memeriksa akun Facebook tersebut, tiap orang rata-rata menghabiskan waktu sekitar 2 menit (Musofa, 2013). Studi dari Oxygen Media and Lightspeed Research juga melihat pada kebiasaan wanita usia 18 hingga 34 tahun tentang sosial media. Hasilnya menyatakan jika 34 persen wanita mengatakan bahwa hal yang mereka lakukan pertama kali ketika bangun tidur adalah mengecek akun Facebook-nya; dan 39 persen wanita mengaku kecanduan Facebook (Firmanza, 2010).

Menurut hasil wawancara, para kelompok karyawan perusahaan di berbagai industri juga aktif mengakses Facebook. Survei yang dilakukan oleh JobStreet.com menunjukkan bahwa sebanyak 81 persen responden mengaku mengakses media sosial saat bekerja. Survei ini dilakukan kepada sebanyak 14.000 karyawan dari berbagai perusahaan dan industri. Sebanyak 51 persen dari responden juga mengungkapkan mereka cenderung mengunggah apa yang terjadi di kantor melalui media sosialnya (Wilda, 2016).

Perusahaan Terbatas (PT) XXX Indonesia, adalah salah satu cabang perusahaan di Singapura yang bergerak di bidang marketing event. Perusahaan ini terdiri dari karyawan-karyawan dari berbagai usia yang masih produktif bekerja. Hasil wawancara menyebutkan bahwa generasi milenial yang menjadi karyawan di perusahaan itu memiliki akun Facebook pribadi.

Berdasarkan data di atas, maka tujuan dari studi ini adalah memotret bagaimana pola penyebaran pesan melalui Facebook oleh generasi milenial sebagai karyawan melalui akun Facebook pribadi.

\section{KERANGKA TEORITIS}

Pesan merupakan seperangkat simbol verbal dan/non verbal yang mewakili perasaan, nilai, gagasan atau maksud si sumber. Menurut Effendy, pesan adalah: "suatu komponen dalam proses komunikasi berupa paduan dari pikiran dan perasaan seseorang dengan menggunakan lambang, bahasa/lambang-lambang lainnya yang disampaikan kepada orang lain” (Effendy, 1989). Pesan mempunyai tiga komponen: makna, simbol yang digunakan untuk menyampaikan makna, dan bentuk atau organisasi pesan. 
Pesan dapat dimengerti dalam tiga unsur yaitu kode pesan, adalah sederetan simbol yang disusun sedemikian rupa sehingga bermakna bagi orang lain. Isi pesan, adalah bahan untuk atau materi yang dipilih yang ditentukan oleh komunikator untuk mengomunikasikan maksudnya. Wujud pesan adalah sesuatu yang membungkus inti pesan itu sendiri, komunikator memberi wujud nyata agar komunikan tertarik akan isi pesan didalamnya (Siahaan, 1991).

Pesan terbagi atas pesan dalam komunikasi verbal dan pesan dalam komunikasi non-verbal. Komunikasi verbal adalah komunikasi yang disampaikan komunikator kepada komunikan dengan menggunakan simbol-simbol atau kata-kata, baik yang dinyatakan secara lisan maupun non lisan. Pada penelitian ini kedua pesan tersebut digunakan, baik verbal maupun nonverbal, baik lisan (video) dan tulisan. Pola penyebaran, artinya bagaimana pesan berpindah dari akun yang satu kepara "friends" pemilik akun.

Wilson, Gosling, dan Graham dari Amerika Serikat melakukan penelitian pada tahun 2012. Penelitian dilakukan pada pengguna Facebook khususnya pengguna aktif dari pelajar hingga orang tua. Penelitian ini menggunakan metode kualitatif. Penelitian ini membandingkan artikel-artikel mengenai Facebook kemudian membuatnya menjadi 5 kategori yaitu motivasi menggunakan Facebook, presentasi identitas, peran Facebook dalam interaksi sosial dan keterbukaan privasi dan informasi (Wilson, Gosling, \& Graham, 2012).

Kemudian Bevan dan Akpojivi dari Afrika melakukan penelitian tahun 2015. Respondennya adalah mahasiswa. Penelitian ini menggunakan metode kuantitatif dengan tujuan untuk mengetahui pengaruh dari kepercayaan terhadap situs dan kepercayaan anggota serta kekhawatiran pengaksesan Facebook terhadap kecenderungan siswa generasi Y untuk keterbukaan diri. Kesimpulan dari penelitian ini adalah siswa generasi Y cenderung dapat memuaskan diri untuk membuka diri di Facebook jika mereka mempercayai list pertemanan mereka dan kepercayaan anggota ini secara negatif dipengaruhi oleh kekhawatiran pengaksesan dan secara positif dipengaruhi oleh kepercayaan terhadap situs (Bevan-Dye \& Akpojivi, 2015).

Lai dan Yang di Taiwan pada tahun 2014 melakukan penelitian pada mahasiswa juga, menggunakan metode kuantitatif. Tujuan penelitian ini untuk memahami motif seseorang dalam menggunakan fitur interaksi sosial dan game sosial di Facebook. Hasil yang diperoleh adalah Facebook menyediakan kedua fitur baik untuk berinteraksi maupun game sosial dimana ada beberapa motif dari pengguna seperti kebutuhan interpersonal, kesenangan, perendaman, pencapaian dan mengejar mode (Lai \& Yang, 2014).

Generasi milenial adalah adalah kelompok demografis yang ada setelah generasi X. Peneliti sosial sering mengelompokkan generasi yang lahir diantara tahun 1980 an sampai 2000 an sebagai generasi milenial. Jadi bisa dikatakan generasi milenial adalah generasi muda masa kini yang saat ini berusia di kisaran 15 - 34 tahun. Dibanding generasi sebelum, generasi millennial memang unik, terutama dalam soal penggunaan teknologi dan budaya pop/musik.

\section{METODE PENELITIAN}

Jenis atau tipe penelitian yang digunakan pada penelitian ini adalah deskriptif. Menurut Kriyantono, jenis riset deskriptif bertujuan untuk membuat deskripsi secara sistematis, faktual dan akurat tentang fakta-fakta dan sifat-sifat populasi atau objek tertentu (Kriyantono, 2006). Dengan merujuk pada pengertian tersebut, maka penelitian ini juga bermaksud memberikan gambaran mengenai pola penyebaran pesan yang dimiliki oleh generasi Y melalui akun media sosial Facebook di PT. XXX Indonesia. 
Metode penelitian yang digunakan peneliti adalah metode studi kasus. Menurut Bogdan dan Biklen, studi kasus merupakan pengujian secara rinci terhadap satu latar atau satu orang subjek atau satu tempat penyimpanan dokumen atau satu peristiwa tertentu (Bogdan \& Biklen, 1982). Penelitian studi kasus diharapkan untuk mempelajari secara intensif, mengenai latar belakang masalah, keadaan dan posisi suatu peristiwa yang sedang berlangsung saat ini, serta interaksi lingkungan unit sosial tertentu yang bersifat apa adanya (given).

Cara pengambilan sampel yang digunakan penelitian ini adalah purposive sampling. Purposive Sampling adalah pemilihan sampel berdasarkan pada karakteristik tertentu yang dianggap mempunyai hubungan dengan karakteristik populasi yang sudah diketahui sebelumnnya (Ruslan, 2010). Teknik pengumpulan data pada penelitian ini terbagi atas data primer dan data sekunder. Teknik wawancara dalam upaya pengumpulan sumber data primer pada penelitian ini dilakukan dengan cara tatap muka (face to face interview). Informan dalam penelitian ini adalah karyawan di PT. XXX Indonesia yang memiliki akun sosial media Facebook dengan rentang usia dari 22 sampai 35 tahun.

Pengumpulan data primer dilakukan dengan mengamati atau mencatat suatu peristiwa dengan penyaksian langsung, dan biasanya peneliti dapat sebagai partisipan atau mengamati suatu objek peristiwa yang sedang ditelitinya. Dalam penelitian ini, maka peristiwa yang diteliti adalah pola penyebaran pesan yang dimiliki oleh generasi milenial melalui media sosial Facebook. Teknik analisis data adalah melalui pengkodean (coding).

\section{HASIL PENELITIAN}

Dari data yang dikumpulkan pada penelitian ini, diperoleh hasil penelitian dan dibahas sebagai berikut: Generasi milenial yang diteliti menyatakan bahwa hampir setiap hari mereka melakukan akses ke akunnya dengan menghabiskan waktu sebanyak 15 sampai 60 menit. Karyawan generasi milenial aktif dalam membaca berita ataupun mengunggah foto dan status meskipun lebih jarang dibandingkan generasi X. Facebook memberikan kesan yang positif dan bermanfaat bagi generasi milenial. Namun Facebook juga dapat dijadikan tempat untuk menyebarkan berita bohong demi kepentingan politik.

Facebook mempengaruhi generasi milenial dengan cara membuat mereka terlibat ikut serta menyebarkan informasi dari Facebook. Namun FB tidak sampai mempengaruhi personality para pengguna akunnya, terutama pada generasi milenial.

Karyawan generasi milenial di PT. XXX Indonesia tidak mengetahui tentang Facebook perusahaan dan biasanya tidak menggunakan media sosial Facebook untuk berinteraksi maupun menyebarkan pesan melainkan melalui media sosial lainnya.

Berdasarkan wawancara pada informan, generasi milenial cenderung lebih sering dan lebih aktif mengakses Facebook daripada generasi X. Generasi milenial mengakses Facebook hampir setiap hari dengan durasi waktu 15 sampai 60 menit per hari untuk sekali akses. Sedangkan waktu generasi X mengakses Facebook lebih sulit ditentukan karena mereka sangat jarang mengaksesnya. Ini menunjukkan jika umur, dalam hal ini adalah generasi, yang merupakan bagian dari Cross-culture communication, membuat perbedaan dari segi penggunaan waktu dalam mengakses Facebook (Zlatko \& Maciej, 2017).

Pada umumnya, karyawan generasi X maupun milenial mengakses Facebook pada saat senggang ataupun jenuh bekerja, dan pada saat istirahat. Ketika mengakses Facebook, generasi milenial cenderung untuk membaca pesan, berita, unggahan teman ataupun membagikan berita yang dianggap perlu dibagikan, karena dianggap berguna dan menarik. Namun perbedaannya adalah 
generasi milenial kadang-kadang juga mengakses Facebook untuk mengunggah foto dan status atau mengomentari dan memberikan tanda "like" untuk hal-hal yang menarik atau ketika di-tag langsung pada akunnya. Hal ini berbeda dengan Generasi X di PT. XXX Indonesia yang lebih jarang mengunggah apa pun karena mereka ingin lebih berhati-hati terhadap penggunaan media sosial yang jika disalahgunakan yang dapat menyebabkan masalah hukum. Mereka cenderung mengakses secara tidak langsung melalui akun onlineshop yang terhubung dengan Facebook.

Generasi milenial menggunakan Facebook untuk menilai sikap dan pertemanan mereka. Mereka mengakses Facebook dengan alasan: Pertama, menghabiskan waktu dan menemani pada saat waktu makan siang. Kedua, pelarian dan relaksasi pada saat senggang maupun jenuh bekerja. Ketiga, memperoleh informasi saat membaca berita dan unggahan teman yang menarik dan bermanfaat. Keempat, interaksi sosial dan hubungan personal pada saat chatting pada teman, baik yang sudah lama tidak ditemui atau yang sering ditemui, atau melalui kolom komentar. Kelima, pengawasan terhadap sikap teman yang dijadikan penilaian sikap mereka.

Aktivitas yang dilakukan oleh karyawan baik generasi milenial di Facebook juga merupakan salah satu bentuk perubahan budaya yang dikemukakan oleh McLuhan dalam Teori Determinasi Teknologi. Dalam teorinya, Marshal McLuhan mengemukakan bahwa "Technology has changed the way we communicate" yang berarti teknologi telah mengubah cara manusia berkomunikasi (Nurudin, 2009).

Perubahan budaya lainnya adalah berbeda dengan generasi sebelumnya, yaitu kebiasaan membaca berita dari surat kabar. Sekarang generasi milenial dapat dengan mudah membacanya dari Facebook yang sebenarnya merupakan situs jejaring sosial. Generasi milenial juga dapat dengan mudah mencurahkan perasaannya atau mengekspresikan diri melalui mengunggah status, foto atau video yang dapat dilihat oleh "teman" mereka, baik yang lokal maupun nasional bahkan internasional, tergantung dimana lokasi teman mereka.

Facebook juga dapat menjadi tempat untuk berkomunikasi dengan teman dunia nyata seperti teman bekerja atau teman dunia maya (yang tidak bertemu secara tatap muka), baik yang sudah lama tidak bertemu ataupun yang sering bertemu. Hal ini berbeda dengan generasi terdahulu jika kita ingin berkomunikasi dengan teman/orang lain, kita harus bertemu langsung dengan orang tersebut atau harus memiliki nomor kontak pribadi agar dapat berinteraksi.

Karyawan generasi milenial berpendapat bahwa Facebook adalah suatu sosial media yang bagus dan sangat membantu dalam hal menyebarkan informasi dan berita yang bermanfaat dan terbaru dari seluruh dunia. Facebook juga dapat digunakan untuk berhubungan dengan orang-orang dari seluruh dunia. Jika ada event dari perusahaan, Facebook dapat dijadikan tempat untuk menarik konsumen. Mereka juga menyebutkan jika Facebook bisa dijadikan tempat untuk bertemu dengan teman lama. Salah satu efek negatif dari Facebook menurut generasi milenial adalah Facebook sering disalahgunakan oleh pihak-pihak tertentu untuk menyebarkan berita bohong atau untuk kepentingan politik yang merugikan orang lain.

Dari hasil wawancara, karyawan generasi milenial menyebutkan jika Facebook perusahaan PT. XXX Indonesia memiliki aktivitas yang sangat minim. Mereka cenderung tidak tahu jika perusahaan mereka memiliki akun Facebook karena mereka lebih banyak menggunakan media sosial lainnya untuk menyebarkan pesan atau berinteraksi seperti Whatsapp, Instagram atau langsung melalui telepon. Hal ini menunjukkan jika di PT. XXX Indonesia, Facebook kalah bersaing dengan media sosial lainnya untuk kepentingan komunikasi internal. 


\section{KESIMPULAN}

Berdasarkan pembahasan hasil penelitian yang telah dikemukan, maka disimpulkan bahwa karyawan generasi X di PT. XXX Indonesia memiliki pola penyebaran pesan tersendiri melalui Facebook. Karyawan generasi Y lebih sering dan aktif dalam mengakses Facebook yaitu hampir setiap hari dan menghabiskan 15 sampai 60 menit untuk sekali akses. Biasanya mereka mengakses Facebook untuk membaca berita dan unggahan teman tetapi kadang-kadang juga mengunggah foto dan status atau memberikan tanda "like" dan mengomentari unggahan teman yang dianggap menarik atau ketika di tag langsung pada akunnya.

Nilai positif dari Facebook adalah membantu dalam mendapatkan berita dan informasi dari seluruh dunia. Facebook juga kadang efektif dalam penyebaran pesan dan juga dapat digunakan untuk menarik konsumen. Facebook juga dapat digunakan sebagai alat untuk berinteraksi dengan orangorang di seluruh dunia atau teman lama yang jarang bertemu. Tetapi Facebook juga memiliki hal negatif jika disalahgunakan oleh pihak-pihak tertentu untuk menyebarkan berita bohong. Di PT. XXX Indonesia, Facebook adalah media yang tidak banyak diminati dan digunakan oleh karyawan untuk komunikasi internal.

\section{Daftar Pustaka}

\section{Book}

Bodgan, R., \& Taylor, S. J. (1975). Introduction to Qualitative Research: Methode. New York: John Willey and Sons.

Bogdan, R. C., \& Biklen, K. S. (1982). Qualitative Research for Education: An introduction to Theory aand Methods. Boston London: Allyn and Bacon, Inc.

Bungin, B. (2011). Penelitian Kualitatif: Edisi Kedua. Jakarta: Prenada Media Group.

Effendy, O. U. (1989). Kamus Komunikasi. Bandung: Mandar Maju.

Flew, T. (2008). New Media an Introdruction. Australia: Oxford.

Kaplan, A. M., \& Haenlein, M. (2010). Users of the World, Unite! . The challenges and Opportunities Media, 59-68.

Katz, E., Blumler, J. G., \& Gurevitch, M. (1974). Utilization of Mass Communication by the Individual. Beverly Hills: Sage Publication.

Kriyantono, R. (2006). Teknik Praktis Riset Komunikasi: Disertai Contoh Praktis Riset Media, Public Relation, Advertising, Komunikasi Organisasi, Komunikasi Pemasaran. Jakarta: Kencana Prenada Media Group.

Lyons, S. (2004). An Exploration of Generational values in Life and at Work. Canada: Carleton University: Ottawa.

Maslow, A. H. (1970). Motivation and Personality. New York: Harper \& Brothers.

McQuail, D. (1987). Mass Communication Theory. Jakarta: Erlangga.

Moleong, L. J. (2013). Metodologi Penelitian Kualitatif. Bandung: PT. Remaja Rosdakarya.

Mulyana, D. (2005). Ilmu Komunikasi: Suatu Pengantar. Bandung: Remaja Rosdakarya.

Nurudin. (2009). Pengantar Komunikasi Massa. Jakarta: Rajawali Pers.

Ruslan, R. (2010). Metode Penelitian: Public Relation dan Komunikasi. Jakarta: Rajawali Pers.

Siahaan, S. M. (1991). Komunikasi Pemahaman dan Penerapannya. Jakarta: Gunung Mulia.

Sugiyono. (2012). Metode Penelitian Kuantitatif Kualitatif R\&D. Bandung: Alfabeta.

Surakhmad, W. (1982). Pengantar Penelitian Ilmiah. Bandug: Tarsito.

West, R., \& Turner, L. H. (2012). Introducing Communication Theory: Analysis and Application.

Jakarta: Salemba Humanika. 
Widjaja, H. A. (2000). Ilmu Komunikasi Pengantar Studi. Jakarta: Rineka Cipta.

Zlatko, N., \& Maciej, B. (2017). Exploring the Influence of Personal values and Cultures in the Workplace. USA: IGI Global Business Science Reference.

\section{Journal Article}

Bevan-Dye, A. L., \& Akpojivi, U. (2015). South African Generation Y Students' Self-Disclosure on Facebook. Psychology Society of South Africa, 1-14.

Lai, C.-Y., \& Yang, H.-L. (2014). Determinants and Consequences of Facebook Feature Use. New media and Society, 1-16.

Wilson, R. E., Gosling, S. D., \& Graham, L. T. (2012). A Review of Facebook Research in the Social Science. Association for Pschological Science, 1-10.

\section{Website}

Firmanza, A. (2010, 10 07). 5 Hasil Penelitian Unik Seputar Facebook. Retrieved 11 22, 2017, from Wolipop:

https://wolipop.detik.com/read/2010/10/07/135228/1458027/860/5-hasil-penelitian-unikseputar-facebook

Ismarani, D. (2017, 04 26). Data Pengguna Internet Tahun 2017 dan Apa kesimpulan yang bisa di ambil dari data tersebut. Retrieved 11 07, 2017, from Youth Manual:

https://www.youthmanual.com/post/fun/did-you-know/data- pengguna-internet-tahun-2017dan-apa-kesimpulan-yang-bisa-diambil-dari-data-tersebut

Musofa, D. Z. (2013, 06 12). Kecanduan Facebook, Fenomena lain Jejaring Sosial. Retrieved 11 22, 2017, from Merdeka: https://www.merdeka.com/teknologi/kecanduan-facebook-fenomenalain- jejaring-sosial-sisi-hitam-jejaring-sosial.html

Wilda, R. (2016, 03 14). 81 Persen Karyawan Akui Gemar Akses Media Sosial di Tengah Jam Kerja. Retrieved 10 30, 2017, from Career News:

http://careernews.id/youknow/view/3870-81-Persen-Karyawan-Akui-Gemar- Akses-

Media-Sosial-di-Tengah-Jam-Kerja 